CIFRAS DE HOY

Rev Chil Salud Pública 2014;

Vol 18 (1): 40-42

\section{NO TODOS TIENEN CÁNCER PERO TODOS NOS RESFRIAMOS*}

\author{
Not EVERYONE GeTS CANCER, BUt EVERYONE GETS COLDS
}

Hace ya varios meses se presentó el estudio “Acceso a Medicamentos de Alto Costo y Enfermedades de Baja Frecuencia” que lideró el Dr. Jorge Jiménez de la Jara, académico del Departamento de Salud Pública UC. ${ }^{1}$ El objeto de este estudio alcanzó un impacto público tras la marcha de los enfermos, manifestación que buscó levantar la indefensión de los pacientes frente a enfermedades cuyo tratamiento es de alto costo.

El estudio en cuestión fue una revisión que no busca ser exhaustiva de un tema poco relevado en Chile. Este recogió argumentos desde la evidencia científica, consulta a los actores involucrados, consideraciones bioéticas, jurisprudencia acumulada, mecanismos de financiamiento y pago por los medicamentos de alto costo, buscando aportar al debate y analizar opciones de políticas viables en nuestro país.

El objeto del estudio se centró en las “enfermedades raras”, vale decir de baja frecuencia o prevalencia, y el tratamiento asociado a ellas. Dentro de estos tratamientos se encuentran las drogas huérfanas. Estos medicamentos, por ser tratamientos de enfermedades de baja frecuencia, atienden a un mercado específico muy acotado.

A su vez, para la industria farmacéutica, el costo de I+D y producción es similar al de una droga que genera alta rentabilidad o "blockbuster". Esto implica que, para este sector económico, proyectar un portafolio de lanzamiento de productos de la empresa farmacéutica, o pipeline, ${ }^{2}$ que contemple drogas huérfanas versus blockbusters, resulta económicamente poco rentable. Es más, muchos de los pipelines de industria farmacéutica de I+D se centran en isoformas y sales de drogas que en el pasado fueron éxitos para estas compañías, las denominadas drogas "Me-Too".

\footnotetext{
* Análisis crítico del estudio presentado por la Universidad Católica “Acceso a Medicamentos de Alto Costo y Enfermedades de Baja Frecuencia”

1. http://medicina.uc.cl/noticias/seminario-medicamentos-de-alto-costo-politicas-para-unmejor-acceso

2. http://en.wikipedia.org/wiki/Drug_pipeline
} 
Dado que el público objetivo es altamente específico y muy acotado, la transferencia del costo de $\mathrm{I}+\mathrm{D}$ es asumido en gran medida por los usuarios. A pesar de que estas drogas ostentan la posibilidad de lucrar de una patente, el precio de venta es muy superior al de una blockbuster. Esto puede no deberse a una posición de abuso de parte de la industria hacia los usuarios, como tradicionalmente se difunde, sino más bien a que el mercado total de esta droga, en comparación con el precio de blockbuster, no alcanza a costear la inversión en I+D. Esto, a causa de que su valor de compra sin una intervención del Estado, es alta.

Por tal razón, estos medicamentos representan un gasto catastrófico para las familias en Chile, transversal a todos los quintiles. ${ }^{3}$ Los antecedentes nos deberían impulsar a abrir un debate sobre la seguridad social y el acceso a medicamentos, tal y como ocurre con el reembolso en países OCDE.

Ahora bien, el estudio presenta antecedentes respecto al acceso a medicamentos de alto costo, definiendo propuestas para mejorarlo. Sin embargo, ¿es conveniente focalizar estudios y recursos a enfermedades de baja frecuencia sin que otras de mayor frecuencia estén cubiertas? (Figura 1).

En una entrevista, Juan Francisco Cabello, neuropediatra del Instituto de Nutrición y Tecnología de los Alimentos (INTA), dice lo siguiente: “...chilenos viviendo con ciertas enfermedades mueren por no tener acceso a terapias, $\mathrm{y}$ no porque estas terapias no existan". ${ }^{4}$ El problema es que esta afirmación funciona tanto para enfermedades de baja frecuencia (cuadrante 4 de la Ilustración 1) como para las enfermedades comunes y que poseen medicamentos de bajo costo (cuadrante 1 de la Ilustración 1). La diferencia está en que en el segundo caso se entiende por "cubierto" y por ende se ignora, pese

3. Cid, Prieto, 2010; Cid, Prieto. "Gasto de Bolsillo en salud: el caso de Chile 1997 y 2007, RevPanam Salud Pública OPS/OMS. (Datos EPF---INE 1997 y 2007).

4. http://www.lahora.cl/2011/03/28/01/noticias/ salud/11-7725-9-precursor-de-ley-de-drogas-huerfanasrecalca-importancia-de-legislar.shtml

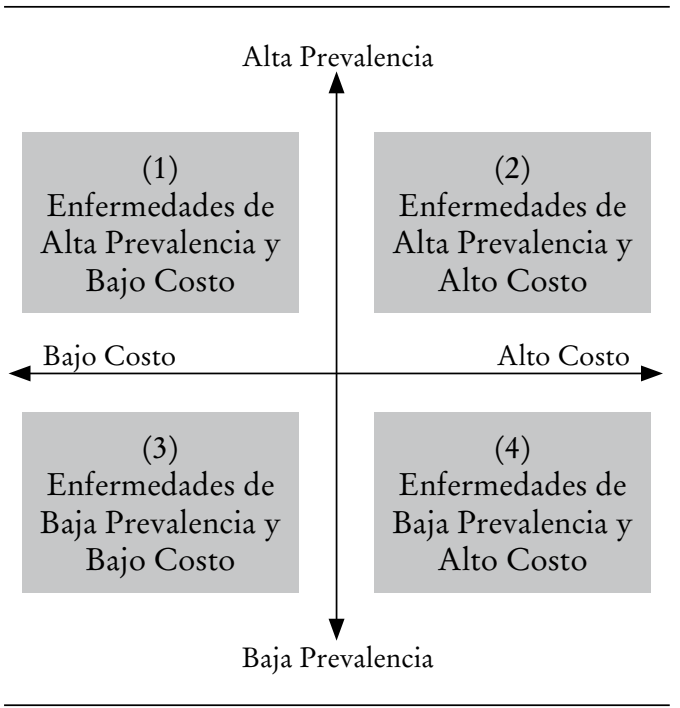

Ilustración 1. Construida a partir de información extraída del documento "Acceso a Medicamentos de Alto Costo y Enfermedades de Baja Frecuencia”)

a que existen documentos oficiales que demuestran este abandono de deberes por parte del sistema público. ${ }^{5}$

Volviendo al estudio, la revisión de antecedentes muestra la existencia de arbitrariedades en el acceso a estos medicamentos, y releva la importancia de las organizaciones de pacientes como "grupos de presión", pero a su vez presenta la necesidad de institucionalidad que permita la evaluación de tecnologías de salud (ETESA), protocolos claros y las politicas basadas en evidencia. Se han tomado acciones en relación a esta primera necesidad, ${ }^{67}$ pero el debate se ha centrado solo en los medicamentos de alto $\operatorname{costo}^{8}$ y poco en la "Política Nacional de Medicamentos Integral”, como lo promueve la OMS. ${ }^{9}$

5. Informe de Fiscalización $N^{\circ}$ 26. Santiago, Septiembre 24 de 2007. Superintendencia de Salud.

6. Resolución Exenta N806 agosto 2009

7. http://www.ispch.cl/noticia/19172

8. 15/10/2013. El Mercurio. "Financiaran farmacos de alto costo para 563 pacientes de diez enfermedades en 2014”

9. http://apps.who.int/medicinedocs/es/d/Js5410s/ 4.1.3.html 
La falta de procedimientos claros por parte del Estado, y por otro lado la relevancia que adquieren los grupos de presión (manipulables por la industria u otros grupos de interés) explicita la fragilidad de nuestro sistema de salud en materia de acceso a medicamentos. Esto puede dar lugar a espacios para corrupción ("bolsones de corrupción") en el sistema, en donde el "caso a caso" y las decisiones en base a presiones, por medio de la manipulación de la "agenda", son regla y no excepción.

El Mapeo de Actores es un ejercicio interesante, y una buena manera de revisar las interacciones entre los actores involucrados, lo que permite pensar en un replanteamiento (o evolución) de las instituciones e institucionalidad que se condiga con las necesidades y demandas de la población.

La fuente de financiamiento más relevante de la salud en Chile ha sido el gasto de bolsillo, siendo la forma de financiamiento menos justa y menos eficiente, según la OMS. ${ }^{10}$ La seguridad social y el andamiaje institucional que permita un financiamiento y aseguramiento de acceso a drogas en nuestro país es inexistente. El estudio de la Universidad Católica trata este tema de una manera "aséptica”, y no integra el tema revisado con otras políticas de salud y de medicamentos a nivel nacional. Es importante revisar las políticas en su conjunto, no como islas independientes, para plasmar una política farmacéutica coherente y alineada a las políticas de salud de Chile.

"Un sistema sanitario no es bueno por lo que gasta o por quién lo gasta. Es bueno por los resultados sanitarios que genera por cada unidad monetaria invertida". ${ }^{11}$

10. http://www.eclac.org/publicaciones/xml/9/32759/sps141_LCL2879.pdf

11. Informe en: Zerda A et al. Health Insurance Systems and Access to Medicines (Sistemas de Seguros de Salud y Acceso a Medicamentos). Buenos Aires, ISALUD, 2001, ISBN 9275323534 (ISBN 927512353 5). 